\title{
The Development of Hopping: An Observation Checklist for Educators 單足跳的進展程度：教育者的觀察清單
}

\author{
Karen P. NONIS \\ Nanyang Technological University/ \\ National Institute of Education, \\ SINGAPORE \\ 嘉偷羅爾斯 \\ 新加坡南洋理工大學／國立敉育學院
}

Helen E. PARKER

The University of Notre Dame, The University of Western Australia,

Western Australia, AUSTRALIA

海倫畢嘉

西澳洲諾特登大學
AUSTRALIA

臒爾羅健

西澳洲大學

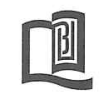

\begin{abstract}
This paper provides an observation checklist of the developmental stages of components of repetitive hopping-in-place and describes performance differences in hopping on the preferred and the non-preferred foot by children and adults. Females aged 3-7 years and 18 - 30 years performed the task of hopping-in-place on their preferred and non-preferred limb on three separate sessions. A behavioural checklist was used to describe the developmental sequence for leg and arm actions, trunk lean, balance control and foot landing style. Age differences in developmental levels in component actions were revealed in both the preferred and non-preferred limbs. The utility of a checklist which details the developmental stages of component parts of hopping and the need to analyse preferred and non-preferred limbs to more objectively quantify the quality of performance are discussed.
\end{abstract}

\section{摘 要}

這份報告提供「重複單足跳」發展階段的觀察清單，並形容對於成人和小孩在選擇「較喜歡」與「較不喜歡」的腳之間單足跳的 不同表現。女性年齡介於三至七歲和十八至三十歲參與了這項選擇「較喜歡」與「較不喜歡」的腳之間單足跳的三個各別測試。對於 腿和臂的行動、腿部肌肉(trunk lean)、身體平衡的控制和足的著陸風格則是以一份行為式的清單來形容。年齡的差距在發展水準的組 成部分上對於選擇「較喜歡」與「較不喜歡」的腳之間單足跳有一定的影響力。使用檢查單可更客觀地詳述對以上單足跳的發展階段 以及分析在選擇「較喜歡」與「較不喜歡」的腳之間的需要。

\footnotetext{
* The data reported here formed part of the first author's Science Honours research in the Department of Human Movement and Exercise Science and was supported by a Special Research Grant of the University of Western Australia.
}

\section{Introduction}

Hopping is a locomotor skill in which the same leg is used for take off and landing. It is a play skill which children acquire in early childhood and which shows a clear lateral preference in the choice of the support limb for hopping. Children use hopping in combination with other locomotor patterns in games when playing hopscotch or skipping or as a fundamental footwork pattern used to suddenly arrest forward movement. Repetitive hopping, either forward or in-place, is also included in several clinical assessments of motor skill as an indicator of gross motor coordination development (Carpenter, 1940; Denckla, 1974; Johnston, Crawford, Short, Smyth \& Moller, 1987). Hopping was shown to be one 
gross motor task which discriminated best between poorly coordinated and normal children (Johnston et al., 1987; Smyth, Johnston, Short \& Crawford, 1991).

Description of the proficiency of hopping as it increases with age can be found in various sources (Corbin, 1983; Denckla, 1974; Keogh \& Sugden, 1985; Wickstrom, 1983). Normally, a single hop on either leg is seen by the age of 41 months, 1 to 3 hops can be performed by 43 months, 4 to 6 hops by 46 months, 7 to 9 hops by 55 months and up to 10 hops by 60 months. By the time the child reaches the age of 66 months, up to 5 repetitive hops-in-place on either foot is possible (Keogh \& Sudgen, 1985). Denckla (1974) reported that at 5 years of age $85 \%$ could hop 12 times and only $15 \%$ were able to complete 50 repetitive hops on one foot. At 6 years only $85 \%$ could hop 25 times and $20 \%$ could perform 50 hops on either foot. From 7 to 10 years, however, over $85 \%$ of each group could complete 50 hops.

Such normative data suggest that limb preference for hopping may be established at the earliest hopping attempts. However, Nonis (Unpublished Thesis, 1996) longitudinal investigation of girls' choice of their preferred limb for hopping changed over time. Few studies report the acquisition timetable of hopping on the non-preferred foot (Denkla, 1974; Gabbard \& Bonfigli, 1987). Denckla (1974) found that the difference in hopping between the right and left feet was less than 5 hops for $80 \%$ of children at ages 5 and 6 years and increased to $90 \%$ of children between 7 to 10 years of age. Therefore it appeared that the difference in performance between the limbs diminishes with increasing age. Gabbard and Bonfigli (1987) reported that by age 5 years $94 \%$ of children had already established stable foot preference. Gabbard's (1989) study of 4-year-old's reported that $46 \%$ of the children were right footed, $46 \%$ were unbiased and $4 \%$ were left footed. As a group, the right preferred children out-performed those who were yet to establish foot preference. Although individual data showed exceptions to this, Gabbard (1989) concluded that earlier establishment of foot preference may lead to better coordination. It is apparent that more research is required to identify the establishment of foot preference and the timetable of development of both feet. We do not know whether the non-preferred foot merely lags the performance of the preferred foot or whether it shows a different coordination pattern and if, as Denckla's (1974) data imply, the non-preferred foot's performance catches up to that of the preferred foot can such development be accelerated with extra training.
Many studies describing hopping have reported gender differences, with girls consistently performing better than boys (Halverson \& Williams, 1985; Keogh, 1968, 1969). Such information has implications for determining normative standards of performance and for subject selection in research. By five years of age, girls were placed at more advanced developmental steps when compared to boys (Halverson \& Williams, 1985) and hopped on the balls of their feet whereas boys hopped flat-footed (Wilson, 1983). Keogh $(1968,1969)$ reported that girls exhibited a higher passing rate and were a year ahead of the boys at ages six and seven years for limb and body control tasks, including hopping tasks. Approximately 50 percent of the girls in Keogh's study accomplished the task of alternate hopping at six years of age and by age eight years, 90 percent of all girls could do so whereas boys aged six years did not achieve this level of performance. In contrast to these studies, Denckla (1974), failed to find difference in the number of repetitive hops-in-place performed on each leg by boys and girls aged from 5 to 10 years. It appears, then, that by assessing the quality of performance rather than the quantity of performance significant gender differences may unmasked.

These differences have been explained in terms of biological and social factors. Skeletal aging has shown that from birth young females have advanced biological maturity (Greulich \& Pyle, 1959). However, social influences related to children's upbringing (Nordberg, Rydelius \& Zetterstrom, 1991) and the games played during the school years (girls typically play hopscotch and skipping more than boys, Sutton-Smith, Rosenberg $\&$ Morgan, 1963) would also account for some of the performance difference.

Current checklists which assess hopping proficiency are for "forward hopping" and they vary in their approach by assessing either the whole body (Seefeldt \& Haubenstricker, 1982; Wickstrom, 1983) or the actions of body components (Halverson \& Williams, 1985; Roberton \& Halverson, 1984, 1988). The body components type of checklist also vary in the number of action components assessed and the number of developmental steps included. For example, Williams (1983) described three age-related 'stages' in the development of hopping forward - Stage 1 (3 years), Stage 2 (4 years) and Stage 3 (5 years) - for the trunk and head position, the arm and leg action and the overall control of the movement components. By contrast, both Roberton and Halverson $(1984,1988)$ and Halverson and Williams (1985) described the developmental levels in 'hopping forward' as a variable number of 'steps' rather than 'stages', depending on the action component being 
assessed and did not associate particular normative ages with these steps. In this study, we included the leg and arm actions from Roberton and Halverson's $(1984,1988)$ checklist.

The 'components part approach' was used in this study because research on hopping forward (Roberton \& Halverson, 1984, 1988; Williams, 1983) had shown that the developmental timetable of the component parts can vary within a single age group. It is common to find some children whose leg action develops in advance of their arm action, or vice versa, for a particular task (Roberton \& Halverson, 1988). Not only does children's motor development proceed at an individual pace overall compared to their peers but so do the component parts of the action.

The purpose of this paper was to develop a checklist for coding the performance proficiency of "hopping-in-place" and to describe the developmental progressions observed in young females from the ages of 3.5 to 7.5 years as compared with adults. Since the development of hopping on each foot has received limited research attention, this paper provides a description of the developmental progression of various components of the action when hopping is performed on each foot. Only female subjects were chosen because gender differences in hopping proficiency have been reported.

\section{Method}

\section{Participants}

The participants comprised a total of 40 normally developing, female volunteers aged between 3.5 and 7.5 years and adults. All subjects were classified as having normal coordination based on the gross motor task scores of the McCarron Assessment of Neuromuscular Development (MAND, McCarron, 1982).

Four age groups of 10 each were formed. Group 1 were aged between 3.5 and 4.0 years $(\mathrm{M}=3.8, \mathrm{SD}=0.3)$, Group 2 were aged between 4.5 and 5.5 years $(\mathrm{M}=5.2, \mathrm{SD}=0.3)$, Group 3 were aged between 6.5 and 7.5 years $(\mathrm{M}=7.0, \mathrm{SD}=0$. $3)$ and Group 4 were adults aged from 18 to 30 years $(M=23$, $\mathrm{SD}=3.4$ ).

\section{The Task of Repetitive Hopping-in-place}

Each subject hopped in-place at their self-chosen, comfortable pace on an AMTI strain gauge force plate (Advanced Mechanical Technology Inc, $0.6 \mathrm{~m} \times 1.2 \mathrm{~m}$ ). Subjects hopped without any footwear while looking straight ahead at a height adjustable target which helped to maintain a central position on the force platform. The preferred limb for hopping was recorded as the leg the subject felt most comfortable using to hop. The sagittal view of hopping on each leg, at each of three test occasions scheduled within the one week, was recorded on VHS video for the checklist. Hopping trials were for five seconds duration during which time up to twelve hops were completed. Trials for the youngest subjects (3.5 - 4 . $0 \mathrm{yrs}$ ) consisted of as many sequential hops as could be performed. The testing area was screened from the rest of the laboratory in order to reduce, as much as possible, the effect of any distractions which might adversely affect the subject's performance.

The participants gross motor coordination was assessed by the gross motor component of the MAND (McCarron, 1982) test battery. Of particular interest was the time subjects spent balancing on one foot with their eyes open. The static balance score was the time achieved (up to a maximum of 30 s) by each foot. This data was compared with the ratings of balance control during hopping.

\section{The Checklist for Hopping-in-place}

Prior to coding the hopping proficiency on each leg, trials from the three sessions were viewed and developmental criteria established for the hopping checklist based on Roberton and Halverson's $(1988,1984)$ and Halverson and Williams' (1985) checklists for hopping forward. Five components of hopping proficiency were assessed for each subject which included the leg and arm actions, trunk lean, balance control and foot landing style (see Tables 1-5). Once each group's performance ratings on a component was completed, the number of subjects tallied at each Stage was converted to a percentage score out of $n=10$. The third experimental session was chosen for assessment since it was felt that this session would provide the children's most typical hopping performance. 
Table 1. Developmental Sequence for Leg Action in Hopping-in-place.

Developmental Sequence

Description

Stage 1: Fall and Catch

Stage 2: Pull-Up

Stage 3: Swing Leg

Stage 4: Full Drive
The child changes hopping legs and may revert to jumping on two feet. Loses balance frequently. Not able to hop continuously.

2 or 3 hops in sequence with minimal flight. Swing leg does not assist in hopping - held up to counter-balance the movement.

At take-off the support leg is flexed at the knee.

Flight is achieved by flexing at the hip resulting in the support leg being pulled towards the body.

Swing leg is held stiffly at 90 degrees flexion - minimal assistance.

Minimal drive in the vertical direction.

Non-support leg begins to swing in assistance with take-off.

Nearly full extension of the support leg at take-off.

Nearly full drive is achieved in the vertical direction.

Non-support leg swings in a circular manner assisting the hop, is less flexed than previous stages and is held in a relaxed and but controlled position.

Support leg shows full knee extension at take-off.

Table 2. Developmental Sequence for Arm Action in Hopping-in-place.

Developmental Sequence

Description

Stage 1: Bilateral Reactive

Stage 2: Bilateral Inactive

Stage 3: Beginning-to-Assist Asymmetrically/Symmetrically

Stage 4: Complete Assistance Asymmetrically/Symmetrically
Arms deter the hopping.

Arms held stiffly at the elbows.

Move in an uncontrolled manner - forearms sway stiffly in the horizontal plane, wrists are loose and hands flap about.

Arms held in a controlled manner although still stiff.

Still does not assist hopping.

Arms still held stiffly but begin to flow with the leg action.

The assistance may either asymmetrically or symmetrically.

Arms assist hopping completely - a relaxed movement coordinated with the smooth action of take-off hopping.

Arms may mirror each other (symmetrical pattern) or move in opposition to each other (asymmetrical). 
Table 3. Developmental Sequence for Landing Action in Hopping-in-place.

Developmental Sequence

Stage 1: Flat Foot Landing

Stage 2: Ball Landing Minimal Heel Contact

Stage 3: Ball-to-Heel Roll
Description

Landing on the ball of the foot and heel simultaneously.

The ankle joint is rigid.

Impact with the floor is with the ball of the foot.

Increased ankle flexion on landing compared to

Stage 1 but insufficient enough to allow the heel to contact the floor.

Impact is with the ball of the foot, ankle flexion occurs to lower the weight onto the rest of the foot.

The heel makes contact with the floor.

Smooth rocking action from ball to heel, and to ball prior to takeoff.

Table 4. Developmental Sequence for Trunk Lean in Hopping-in-place.

Developmental Sequence

Stage 1: Forward Lean

Stage 2: Near Vertical Alignment

Stage 3: Vertical Alignment
Description

Extreme forward lean - forward flexion of the trunk at the level of lumbar vertebrae 3-4 (L3-4).

Uncontrolled posture.

Slight forward trunk lean at L3-4.

More control over the posture with greater relaxation.

Vertical alignment of the trunk in a relaxed and well controlled posture.

Vertical alignment is quickly restored by rapid accommodation to

disturbances to movement.

Table 5. Developmental Sequence for Balance Control Lean in Hopping-in-place.

Developmental Sequence Description

Stage 1: Uncontrolled

Stage 2: Semi-controlled

Stage 3: Complete Control
Minimal balance control - much movement from the beginning position on the floor seen.

Balance re-gained by frequent propping with the non-support leg.

More overall control with less movement from the beginning position.

Tension still evident in hopping.

In-place hopping achieved - little movement from the beginning position on the floor observed.

Lateral and fore-aft disturbances are smoothly accommodated.

Relaxed and comfortable hopping. 


\section{Results}

Leg Action (see Figure 1). For preferred leg action, $30 \%$ of the youngest children (Group 1, $\mathrm{n}=10$ ) were classified at Stage 1 (Fall and Catch) and 70\% Stage 2 (Pull-Up). All children in Group 2 were still at Stage 2 (100\% of 10 subjects) while children in Group 3 were represented in Stage 2 (30\%), Stage 3 (60\%, Swing Leg) and Stage 4 (10\%, Full Drive). All adults were classified at Stage 4.

When hopping on the non-preferred leg, both Group 1 and Group 2 decreased proficiency, with $50 \%$ of the first Group and $10 \%$ of Group 2 being coded at Stage 1. However, Group 3 did not show a regression in performance, with more children (20\% in comparison to $10 \%$ for preferred hopping) being represented at Stage 4. Adults' non-preferred hopping was found to be as proficient as preferred hopping, with $100 \%$ being at Stage 4.

Figure 1. The Percentage of Cases for Each Age Group at each Developmental Stage of Leg Action for Hopping on the Preferred and Non-preferred legs.

\section{LEG ACTION}

(a)

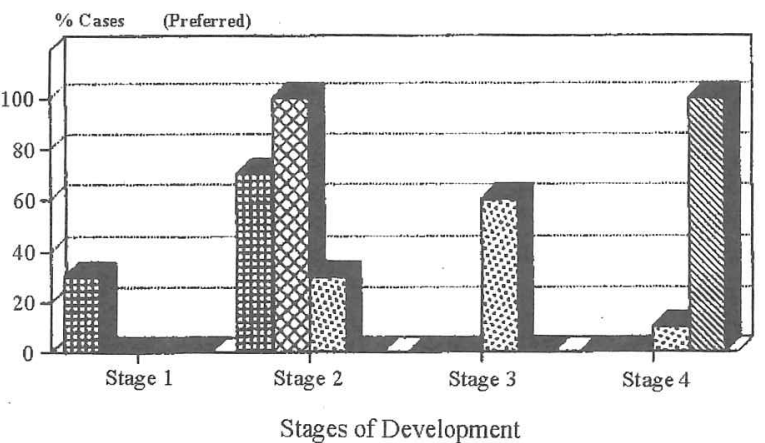

(b)

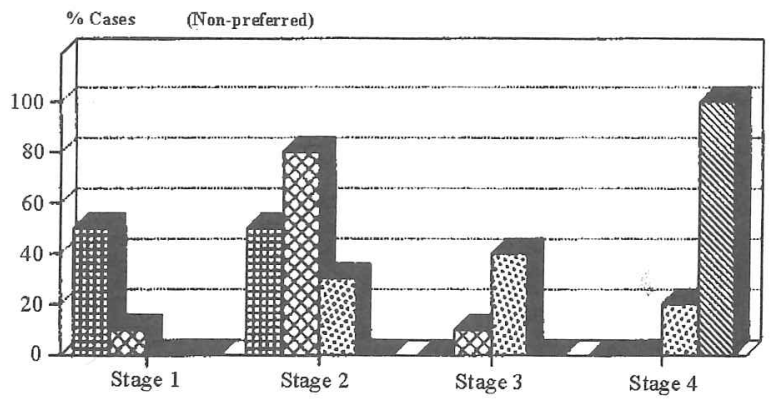

Stages of Development

田 3.5 4.0 yrs $\bigotimes 4.5 \cdot 5.5 \mathrm{yrs} \quad 0.5 \cdot 7.5 \mathrm{yrs}$ Adults
Arm Action (see Figure 2). For arm action in preferred hopping, the children were represented at the various stages in age-related proportions, the Adults were found only at the most mature stage and were developmentally separated from Group 1. Group 1 had $70 \%$ at Stage 1 (Bilateral Reactive) and 30\% at Stage 2 (Bilateral Inactive). For children in Group 2, 20\% were represented at Stage 1,60\% at Stage 2 and 20\% at Stage 3 (Beginning to Assist). Group 3 children were represented in higher development levels with $30 \%$ at Stage 2, 50\% at Stage 3 and 20\% reaching Stage 4 (Complete Assistance). All of Group 4's subjects were at Stage 4 of the arm action.

For non-preferred hopping, only Group 3 showed greater representation at more inefficient stages of arm action in comparison to preferred hopping. All Adults remained at Stage 4, each of the youngest groups showed a slight improvement in the number of children at the more mature stages ( $40 \%$ of Group 1 at Stage 2 and 30\% of Group 2 at Stage 3). For some children in Group 3, however, arm action regressed to less efficient stages with $10 \%$ being coded at Stage 1, $40 \%$ at Stage 2, $40 \%$ at Stage 3 and $10 \%$ being at Stage 4.

Figure 2. The Percentage of Cases for Each Age Group at Each Developmental Stage of Arm Action for Hopping-in-place on the Preferred and NonPreferred Legs.

\section{ARM ACTION}

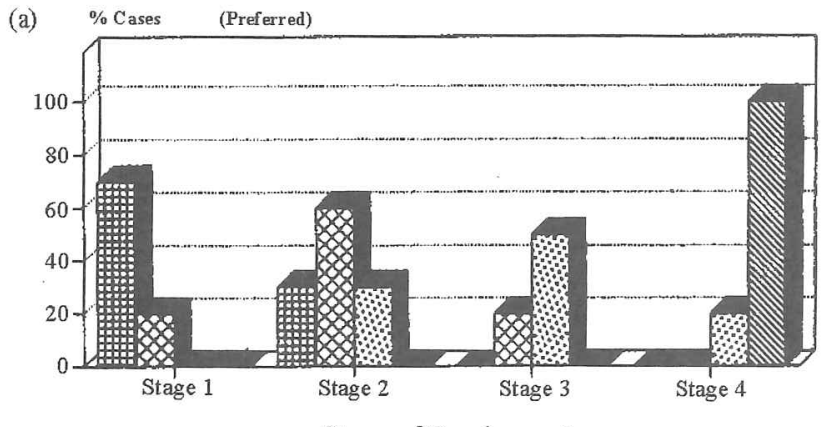

Stages of Development

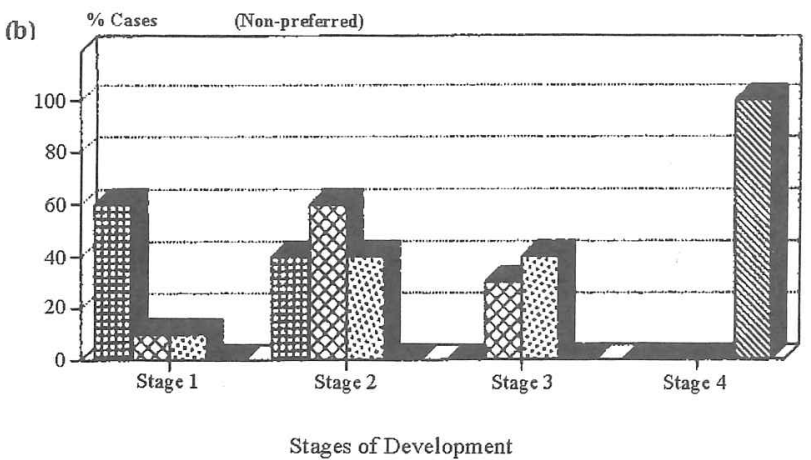

田 3.5 - 4.0 yrs $\bigotimes 4.5 \cdot 5.5$ yrs $\quad \circ 6.5 \cdot 7.5$ yrs $\$$ Adults 
Trunk Lean (see Figure 3). Trunk lean in preferred hopping showed a somewhat different age-related distribution compared to leg and arm action. Groups 1,2 and 3 were all represented at Stages 1 (Forward Lean) with the coding percentages being $70 \%, 40 \%$ and $10 \%$ respectively. All the children's groups were represented at Stage 2 (Near Vertical Alignment) with $10 \%$ of Group 1, $60 \%$ of Group 2, $80 \%$ of Group 3 and $10 \%$ of Group 4. For the most mature posture (Stage 3, Complete alignment), $10 \%$ of Group 3 and $90 \%$ of Group 4 were coded as showing this trunk alignment while hopping.

For hopping on the non-preferred foot, the trunk alignment appeared to regress to a lower level for Group 2 only (60\% at Stage 1 and $40 \%$ at Stage 2). For the other groups, a greater number of subjects were found to adopt more vertical alignment. In Group 3, the number of children at Stage 3 increased to $40 \%$ although one case was still coded at Stage 1. The one adult at Stage 2 alignment for preferred hopping showed Stage 3 alignment in non-preferred hopping (i.e. $100 \%$ of Group 4 now at Stage 3).

Figure 3. The Percentage of Cases for Each Age Group at Each Developmental Stage of Trunk Lean for Hopping-in-place on The preferred and Nonpreferred legs.

\section{TRUNK LEAN}

(a)
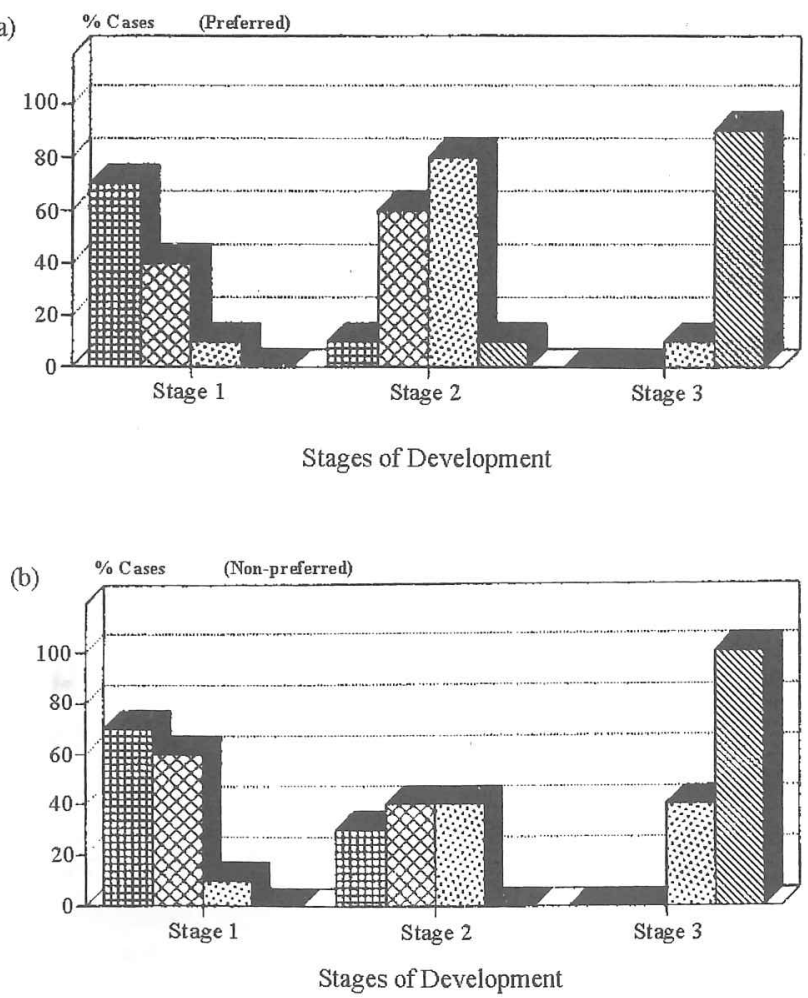

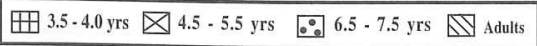

Balance Control (see Figure 4). Analysis of this component for preferred hopping showed that the youngest children's performance could be coded across all the balance stages. Eighty percent of Group 1 were at Stage 1 (Uncontrolled) with $10 \%$ at each of Stages 2 (Semi-controlled) and 3 (Full Control). Seventy percent of Group 2 were represented at Stage 2 and 30\% at Stage 3. The balance control of Group 4 showed equal representation at each of Stages 2 and 3 (i.c. $50 \%$ of the group).

For non-preferred hopping, imbalance was more evident, with all groups showing a reversion to a lower balance stage. No subject from Group 1 showed "Full Control", with 90\% showing "Uncontrolled" balance and 10\% "Semi-controlled" balance. Group 2 showed a major shift to "Uncontrolled" balance as well, with $70 \%$ of the group being coded at this stage, $20 \%$ at Stage 2 and $10 \%$ at Stage 3. One subject from Group 3 also regressed to Stage 1, 50\% remained at Stage 2 with a reduction to $30 \%$ of the group performing at Stage 3 balance. Adults' balance was also adversely affected by hopping on the non-preferred foot, with $20 \%$ of the group regressing to the "Semi-controlled" balance criteria.

Figure 4. The Percentage of Cases for Each age group at each developmental stage of balance control for hopping-in-place on the preferred and nonpreferred legs.

\section{BALANCE CONTROL}

(a)

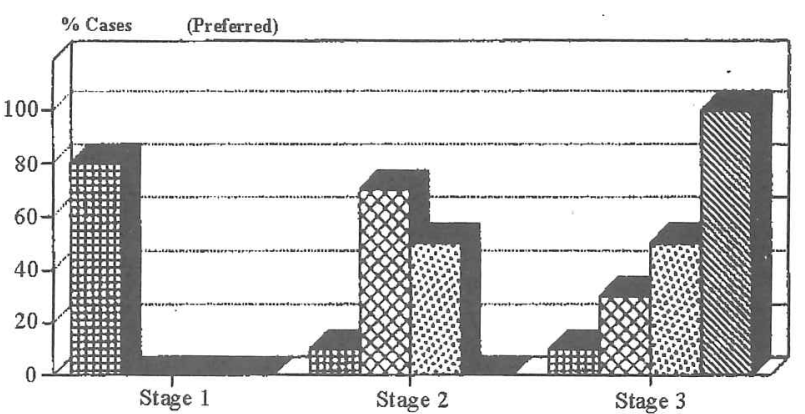

Stages of Development

(b)

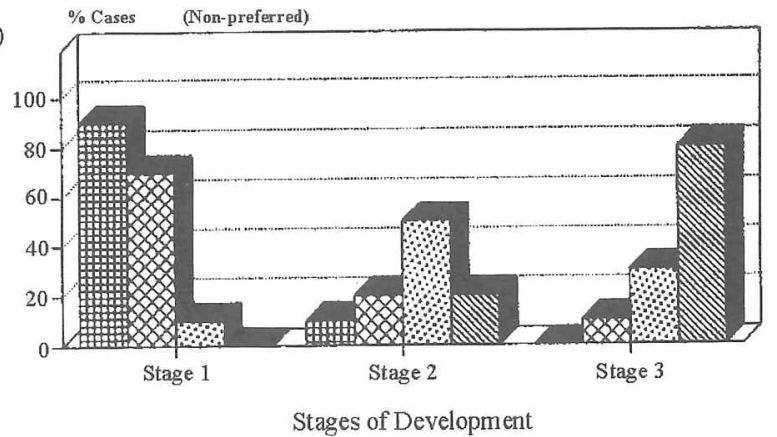

田 3.5 - 4.0 yrs $\bigotimes 4.5-5.5 \mathrm{yrs} \quad$ 용 $6.5-7.5 \mathrm{yrs}$ Adults 
To corroborate these behavioural findings, performance on the MAND "Standing balance" task with the preferred and non-preferred leg showed similar developmental differences (see Table 6). There was an age-related increase in balance time recorded for both the preferred and non-preferred legs. The youngest group of children had the least control over static balance in either leg compared with the older children. The Adult group showed balance scores on both feet close to the ceiling of 30s. An Age x Foot repeated measures ANOVA revealed a significant main effect only for Age in the balance scores $[\underline{F}(3,72)=35.5, p<0.05]$. The apparent difference in balance score seen in Table 6 between the feet was not statistically significant.

Table 6. Standing Balance Eyes-Open for the Preferred and Non-Preferred Legs (in seconds).

AGE GROUP

Preferred Non-preferred

$\begin{array}{lcc}\text { Group } 1 \text { (3-4 yrs) } & 6.9 & 4.9 \\ \text { Group } 2 \text { (4.5-5.5 yrs) } & 16.6 & 14.7 \\ \text { Group } 3 \text { (6.5-7.5 yrs) } & 22.8 & 23.3 \\ \text { Group } 4 \text { (Adults) } & 29.2 & 27.8\end{array}$

Foot Landing Style (see Figure 5). Analysis of this component for preferred hopping showed that most of Group $1(60 \%)$ were categorised at Stage 1 (Flat foot) although $20 \%$ of this group were rated at each of Stages 2 (Ball landing - minimal heel contact) and 3 (Toe landing to heel roll). Older children were also categorised at Stage 1 with $50 \%$ of Group 2 and 30\% of Group 3 subjects being represented. Group 2 children were also represented at Stage 2, with $40 \%$ showing this landing technique. None of Group 3 showed Stage 2 landing technique. All age groups were represented at Stage 3, the most mature, efficient landing technique, with $20 \%$ of Group 1, 10\% of Group 2, 70\% of Group 3 and $90 \%$ of Group 4 achieving the performance criteria of this stage.

Landing techniques used in hopping on the non-preferred foot showed a regression to less efficient styles in all groups. Greater numbers of children were coded in the lower stages with Stage 1 showing 70\% of Group 1,80\% of Group 2 and $40 \%$ of Group 3. Stage 2 techniques were seen in subjects of all ages with $20 \%$ of Group 1, $10 \%$ of Group 2, $30 \%$ of Group 3 and 30\% of Group 4. The percentage of subjects showing the most efficient landing techniques was reduced in non-preferred hopping with $10 \%$ of Group 1, $10 \%$ of Group 2, 20\% of Group 3 and 70\% of Group 4 being represented.

Figure 5. The Percentage of Cases for Each Aage Group at Each Developmental Stage of Foot Landing for Hopping-in-place on the Preferred and NonPreferred Legs.

FOOT LANDING
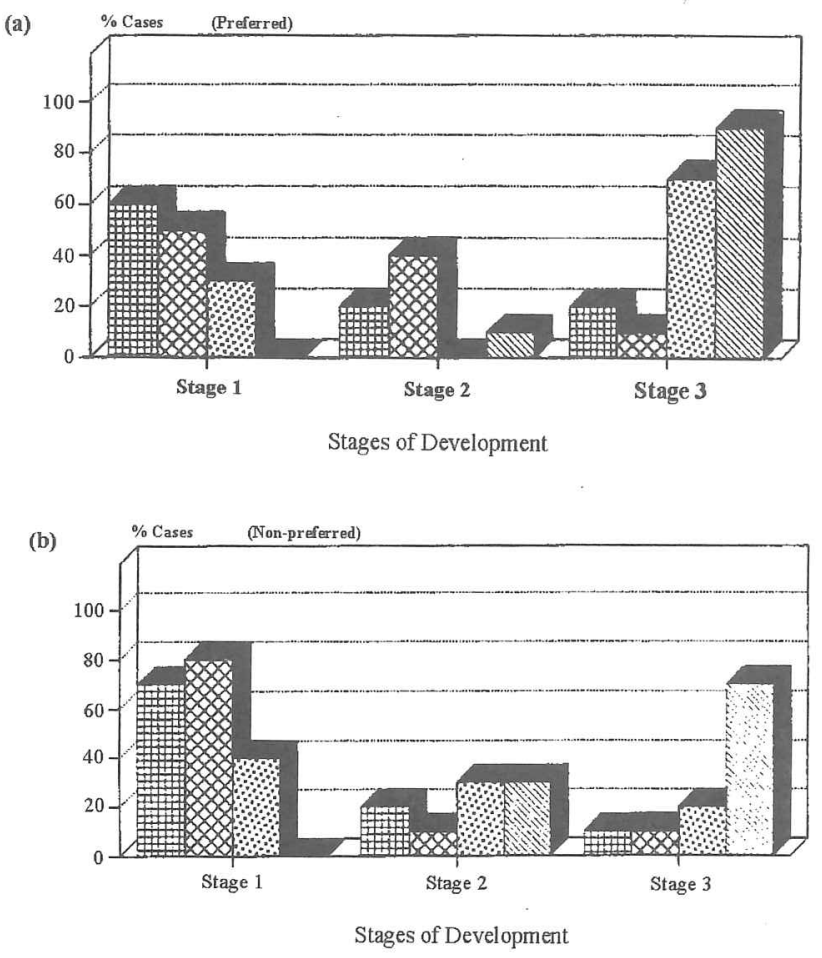

田 3.5 - 4.0 yrs $\bigotimes 4.5 \cdot 5.5$ yrs $\quad 0.5-7.5$ yrs $\quad$ Adults

\section{Discussion}

Analysis of hopping-in-place revealed that as age increased not all components of action increased in proficiency and that not all ages showed a regression to lower proficiency levels when hopping on the non-preferred leg. Arm and leg actions showed the clearest age-related developmental trend, with diminishing representation of the younger children as stages of development increased and increasing representation of the older children in the higher developmental stages. Adults were clearly separated from the youngest children in the proficiency of leg action, arm action and trunk lean. For trunk lean a similar pattern emerged with the proportion of 
children at the less efficient stages increasing as age decreased. For the trunk lean and foot landing components there was greater overlap between the age groups. For example, in the balance control component some children of each group who achieved the most efficient, "Controlled balance" stage although adults were recorded only at this stage whereas $80 \%$ of the youngest group were at the least efficient "Uncontrolled balance" stage. Analysis of foot landing style showed that some children in each age group showed the "Flat foot", "Ball landing-minimal heel contact" and "Toe landing-heel roll" styles while adults hopped with either of the two latter styles.

When hopping on the non-preferred leg, all ages revealed regression to lower levels of performance for balance control and foot landing style. For leg action, however, only adults and Group 3 children maintained performance quality whereas for arm action only Group 3 children showed regression in performance, with greater numbers in the lower performance levels compared to preferred hopping. For the other children and the adults a slight improvement in arm action was found with greater numbers at the more advanced arm action stages. Finally, for trunk lean only Group 2 children showed regression to lower developmental stages whereas all other ages showed some improvement with greater numbers of subjects at higher developmental stages.

These results reveal that although there were age-related differences in the hopping component proficiency, individual differences exist in the relative maturity of the individual components within any one individual. Further, the common assumption of lower performance levels by the non-preferred leg cannot be supported for all components of hopping since some age groups show improvements and others show regressions. Leg action was poorer for non-preferred hopping only in children younger than about 7 years. This corroborates Denckla's (1974) finding that hopping performance of each leg becomes increasingly similar with age. Some regression was shown in foot landing style and balance control for non-preferred hopping in all groups. However, the coding of arm action and trunk lean showed greater numbers of subjects advancing to higher developmental levels. We cannot offer an explanation of why this should occur and thus far there is no published study with which we can compare the finding. However, if the non-preferred leg shows different coordination development than preferred hopping and not just a developmental delay, then the checklist may have to be amended in order to reveal such differences. Validation of the analysis checklist in a longitudinal study is warranted.
The unexpected results for non-preferred hopping questions the method of categorising the preferred leg. Although the preferred hopping leg was decided as being the most comfortable hopping leg for the child, perhaps the younger children are less able to discriminate this difference. Armitage and Larkin (1992) identified that poorly coordinated and 5-6 year old normally coordinated children were unable to make a clear distinction between the relative performance of their legs unless the performance differences were relatively great. Their ability to accurately match the better performing limb with the preferred limb was often in error. In contrast, normally coordinated 8 to 9 year old children could discriminate the better performing limb when there was only a small performance difference between the limbs and showed much greater congruence between best performance and leg preference.

Williams (1983) reported that in attempting to hop forward at 3 years, children tend to step on their non-support foot frequently to regain balance. This feature was also common in the 3.5- to 4-year-olds of the current study with 30\% showing "Fall and Catch" characteristics during preferred hopping increasing to $50 \%$ during non-preferred hopping. The results from the MAND (McCarron, 1982) "Standing balance" test also corroborated differences in balance between the age groups. The youngest group of children had least balance control (relatively short balance times) in comparison to the adults and older children who recorded significantly longer balance times. In conjunction with the more efficient hopping technique shown by the oldest children and adults it appeared that there may be an association between the level static balance control and the acquisition of repetitive hopping-in-place (dynamic balance control). For repetitive hopping-in-place it would appear important to attain static balance on one leg and also to develop control of balance when the base of support is constantly shifting. However, since previous research has indicated that static and dynamic balance are not necessarily correlated and that these abilities load onto different factors in normally coordinated children's motor behaviour (DeOreo \& Wade, 1971; Hoare, 1991), the extent to which the development of static balance may influence the acquisition of repetitive hopping warrants further investigation.

Although Williams (1983) indicated that the mature level of hopping was acquired by 5 years of age, we found that the proficiency of some components of hopping-in-place, even on the preferred leg, were not yet mature by 7.5 years of age. Some of the oldest children exhibited developmental components that were similar to the adults but for the majority of these children there was still room for refinement of their hopping pattern. The apparent lack of agreement in the age 
of maturation of hopping may relate to the increased difficulty of hopping-in-place compared to hopping forward. Proficient in-place hopping requires greater control of propulsive forces to ensure that forward and lateral momentum is minimal while the forces are directed in the vertical direction (Keogh \& Sugden, 1985; Parker, Monson \& Larkin, 1993).

The observation of extreme forward trunk lean (anterior flexion at the level of the lumbar spine) in the youngest children was also linked to the level of balance control and resulting overall performance. Seventy percent of the youngest group who demonstrated extreme forward leaning of the trunk and were also at either the "Fall and catch" or "Pull-up" stage of the leg action and were also rated as having poorest balance control. All of the adults but only $10 \%$ of the oldest children had attained vertical alignment of the trunk while hopping-in-place and were also rated as having the most efficient stage of balance control. However, there were a number of children whose balance and trunk lean ratings did not appear to correspond. For example, only $10 \%$ of the oldest children attained vertical alignment of the trunk but more than this were rated as having the most efficient stage of balance control. Furthermore, some children from Group 1 (10\%) and Group $2(30 \%)$ had also reached this mature stage of balance control. Monson et al., (1991) reported that the youngest children produced an increased force in the anterior-posterior direction and suggested that this could also be indirectly linked to the children's more extreme forward lean of the trunk. It was speculated that this forward lean indicated an uneven weighting of the body mass over the children's base of support, thus affecting their balance and the control of their movement. As well as implicating different rates of neuromuscular development, superior balance control by some of the younger children could be indirectly related to their participation in other activities such as gymnastics or ballet. This factor presents possible areas for further investigation.

The final component analysed, foot landing style, showed a less clear developmental trend as there was overlap in the children's categorisations. Williams (1983) reported that 3year-old's landed flat-footed while 5-year-olds landed on the balls of their feet. The adults and the oldest children in the current study demonstrated a toe-to-heel landing followed by a heel-to-toe rocking take-off action. This style seems to be the most mature form of landing for smooth force absorption and efficient force generation to produce the next hop.

By assessing motor proficiency with a checklist describing the stages of development of component parts of action we have shown that different component parts develop at different rates. Some children's leg component was at a more advanced level than their arm component, while for others the reverse was true. Further, it was revealed that in non-preferred hopping not all components showed a lower stage of development. For leg action, proficiency of the two legs appeared comparable for the oldest children and adults, however, foot landing and balance control showed regression in all age groups. Therefore, it is recommended that in observing the proficiency of children's movement component parts rather than the overall action should be assessed and that performance on both limbs should be classified. Although the data was derived from normally developing children, this hopping checklist may be used to identify specific motor coordination problems in poorly coordinated and special needs. Early intervention programmes incorporating related skills such as balance and hopping could be included in the child's movement experience. The observations made in this study highlight the necessity of including the unique individual and group differences when measuring and grading children's movement performance.

\section{References}

Armitage, M., \& Larkin, D. (1993). Laterality, motor asymmetry and clumsiness in children. Human Movement Science. 14(1-2), 155-177.

Carpenter, A. (1940). Tests of motor educability for the first three grades. Child Development, 11(4), 293-299.

Denckla, M. B. (1974). Development of motor coordination in normal children. Developmental Medicine and Child Neurology, 16, 729-741.

DeOreo, K.D., \& Wade, M.G. (1971). Dynamic and static balancing ability of pre-school children. Journal of Motor Behavior, 3(4), 326-335.

Gabbard, C. (1989). Foot lateralisation and psychomotor control in four-year-olds. Perceptual and Motor Skills, 68, 675678.

Gabbard, C., \& Bonfigli, D. (1987). Foot laterality in fouryear-olds. Perceptual and Motor Skills, 65, 943-946.

Greulich, W. W., \& Pyle, S. I. (1959). Radiographic atlas of skeletal development of the hand and wrist (2nd ed.). London: Oxford Press. 
Halverson, L.E., Roberton, M.A., \& Langendorfer, S. (1982). Development of the overarm throw: Movement and ball velocity changes by seventh grade. Research Quarterly for Exercise and Sport, 53(3), 198-205.

Halverson, L., \& Williams, K. (1985). Developmental sequences for hopping over distance: A prelongitudinal screening. Research Quarterly for Exercise and Sport, 56, 37-44.

Hoare, D. (1991). Classification of movement dysfunction in children: Descriptive and statistical approaches. Unpublished Doctoral Thesis, University of Western Australia, Perth.

Johnston, O., Crawford, J., Short, H., Smyth, T.R., \& Moller, J. (1987). Poor co-ordination in 5 year olds: A screening test for use in schools. Australian Paediatric Journal, $23,157-161$.

Keogh, J. F. (1968). Developmental evaluation of limb movement tasks. (Technical Report 1-68). University of California, Los Angeles, Department of Physical Education.

Keogh, J. F. (1969). Analysis of limb and body control tasks (Technical Report 1-69). University of California, Los Angeles, Department of Physical Education.

Keogh, J., \& Sudgen, D. (1985). Motor skill development. NY: Macmillan.

McCarron, L. T. (1982). McCarron assessment of neuromuscular development (Revised ed.). Dallas: Common Market Press.

Monson, K. P., Larkin, D., \& Parker, H. E. (1991). Developmental changes in ground reaction force of hopping-in-place. In O'Higgins, P. (Ed.), Human biology: An integrative science. Proceedings of the Fourth Annual Conference of the Australasian Society for Human Biology, University of Western Australia, Nedlands: Centre for Human Biology, 297-303.

Nonis, K. P. (1996). A mixed Longitudinal Study of the Development of Lower Limb Preference and Hopping Performance in Girls. Unpublished Doctoral Thesis, The University of Western Australia, Perth.

Nordberg, L., Rydelius, P., \& Zetterstrom, R. (1991). Psychomotor and mental development from birth to age of four years: Sex differences and their relation to home environment. Acta Paediatrica Scandinavica Supplement, 378, 3-25.
Parker, H. E., Monson, K. P., \& Larkin, D. (1993). Symmetrical and asymmetrical motor control in children: Bipedal and unipedal hopping. Human Movement Science. 14(1-2): 179-193.

Roberton, M. A., \& Halverson, L. E. (1984). Developing children - Their changing movement. Philadelphia, PA: Lea and Febiger.

Roberton, M. A., \& Halverson, L. E. (1988). The development of locomotor coordination: Longitudinal change and invariançe. Journal of Motor Behavior, 20, 197-241.

Seefeldt, V. D., \& Haubenstricker, J. L. (1982). Patterns, phases or stages: An analytical model for the study of developmental movement. In J. A. S. Kelso \& J. E Clark (Eds.), The development of movement control and coordination (pp. 309-318). New York: Wiley \& Sons.

Smyth, T. R., Johnston, O., Short, H., \& Crawford, J. (1991). The South Australian Motor Screening Test: An evaluation. Australian Journal of Early Childhood, 16(2), 33-37.

Sutton-Smith, B., Rosenberg, B.G., \& Morgan, E.F. (1963). Development of sex differences in play choices during pre-adolescence. Child Development, 34, 119-126.

Wickstrom, R. L. (1983). Fundamental motor patterns (3rd ed.). Philadelphia; Lea \& Febiger.

Williams, H. G. (1983). Perceptual and motor development. Englewood Cliffs, NJ: Prentice Hall.

Wilson, K. (1983). The effect of task complexity on selected kinematic measures of hopping patterns in children. Unpublished Masters Thesis, The University of Wisconsin, La Crosse.

\section{Correspondence:}

Coordinating Author: K. P. Nonis, Assistant Professor Address: Specialised Education Academic Group, Nanyang Technological University/ National Institute of Education, 1 Nanyang Walk, Singapore 637616 E-mail: kpnonis@nie.edu.sg. 